\title{
ESTÉTICA DA EXISTÊNCIA ESTUDANTIL E ATUAÇÃO DO ASSISTENTE SOCIAL NO ÂMBITO ESCOLAR
}

\author{
Aesthetics of student existence and social assistance in school
}

Dorgival Gonçalves Fernandes ${ }^{1}$

Maria da Conceição Silva Félix ${ }^{2}$

\begin{abstract}
RESUMO: No artigo objetivamos problematizar a questão da estética da existência juvenil e a atuação do/a assistente social no ambiente escolar. Teoricamente nos apoiamos no pensamento de Michel Foucault, principalmente nas noções de estética da existência, constituição do sujeito e governamentalidade. A base empírica constitui-se de dois documentos do CFESS (2012): "A inserção do Serviço Social na Política de Educação na perspectiva do Conjunto CFESS/CRESS: elementos históricos e desafios para a categoria profissional" e "Subsídios para a Atuação de Assistentes Sociais na Política de Educação". As análises demonstram que as possibilidades de atuação do assistente social em função da estética da existência estudantil são muitas e são potencializadas pelo Projeto Ético Político do Serviço Social.
\end{abstract}

Palavras-chave: Juventude estudantil. Assistente social. Estética da existência. Michel Foucault.

ABSTRACT: In the article we aim to problematize the question of the aesthetics of the juvenile existence and the social worker 's performance in the school environment. Theoretically we rely on Michel Foucault's thought, mainly on the notions of aesthetics of existence, constitution of the subject and governmentality. The empirical basis consists of two documents from CFESS (2012): "The insertion of Social Service in Education Policy from the perspective of the CFESS / CRESS Group: historical elements and challenges for the professional category" and "Grants for Assistants In Education Policy". The analyzes show that the social worker's possibilities of action in terms of the aesthetics of student existence are many and are enhanced by the Social Service Political Ethical Project.

Key-words: Youth student. Social worker. Aesthetics of existence. Michel Foucault.

\footnotetext{
${ }^{1}$ Professor do Curso de Pedagogia da UFCG, Campus de Cajazeiras. Possui graduação em Pedagogia e mestrado em Educação pela UFPB, Doutorado em Educação pela UFSCar e Pósdoutorado em Educação pela USP. É líder do Grupo de Estudos e Pesquisas em Educação, Práticas Sociais e Linguagem - GIEPELPS.

${ }^{2}$ Professora do Curso de Serviço Social da UFCG, campus de Sousa. Possui graduação em Serviço Social pela UFPE, mestrado em Serviço Social pela UFPB e é doutoranda em História pela PUC/SP. É membro do Programa de Direitos Humanos - PRODIH - da UFCG Membro do Grupo de Pesquisa sobre Marxismo e Serviço Social.
} 


\section{INTRODUÇÃO}

Neste artigo, constituído no intercruzamento entre os campos da Filosofia, da Educação e do Serviço Social, buscamos problematizar a questão da estética da existência juvenil no ambiente escolar tendo como foco as práticas de dois sujeitos escolares: os estudantes jovens e o/a Assistente social escolar. Sob tal perspectiva lançamos um olhar interpelante sobre a relação desses dois sujeitos quanto à estética da existência juvenil no que tange aos processos de constituição de si do sujeito estudantil e o trabalho do assistente social frente a tais processos constitutivos do sujeito estudante no campo da educação escolar.

Pensar a noção de constituição do sujeito, na perspectiva da constituição de si, implica pensar a noção de estética da existência. Sobre essas noções, Michel Foucault faz duas afirmações importantes que sustentam a elaboração da nossa questão em estudo. A primeira delas, sobre a moral, diz o filósofo que a busca por uma forma de moral a qual todos devessem se submeter parece catastrófica (FOUCAULT, 2004). A segunda, acerca da constituição do sujeito, Foucault (Ibid, p. 290) assevera: [...] o sujeito se constitui por meio das práticas de assujeitamento, ou de uma maneira mais autônoma, através das práticas de liberação, de liberdade [...].

São as práticas de liberação, de liberdade que possibilitam a criação de estéticas da existência entre sujeitos que se ocupam da constituição de si e produzem a vida como obra de arte, centrando-se numa ética de si que se firma na luta contra a submissão da sua subjetividade em conformidade com a moralidade assujeitadora. Sobre a produção da vida como obra de arte, assim se refere Foucault (2013, p. 306):

O que me surpreende é o fato de que, em nossa sociedade, a arte tenha se transformado em algo relacionado apenas a objetos e não a indivíduos ou à vida; que a arte seja algo especializado ou feito por especialistas que são artistas. Entretanto, não poderia a vida de todos se transformar numa obra de arte? Por que deveria uma lâmpada ou uma casa ser um objeto de arte, e não a nossa vida?

Nessa perspectiva, a produção da vida como obra de arte, como estética da existência para os sujeitos jovens estudantes, no âmbito da escola, significa, não obrigatoriamente, e em todos os sentidos, se pautar pela moral socialmente prescrita 
para a escola e pela escola que, de modo disciplinar, pré-estabelece a conduta estudantil certa, desejada e normalizada. Neste sentido, vale considerar a questão suscitada por Pignatelli (1994, p. 137):

Porque falamos tão facilmente sobre o fracasso escolar de um estudante, sobre seu desrespeito para com os professores, sobre seu baixo desempenho em testes padronizados, sua incapacidade em falar e compreender a língua padrão, sobre estudantes 'de risco', e assim por diante, como constituindo 'comportamentos desviantes', e muito pouco sobre essas condições como forma de ação de resistência e como oportunidade para cultivar a agência discente?

É neste sentido que perguntamos sobre as possibilidades da atuação do assistente social escolar na lida com estudantes que apresentam na escola condutas que se desviam da moral prescrita. Assim, as afirmações e questões postas acima são pertinentes para este estudo ao considerarmos o sentido, os objetivos e os modos de operacionalidade da educação escolar brasileira ao longo da sua história, e nesta, a atuação do/a Assistente Social. Nesta perspectiva, nos propomos como indagação a seguinte questão: considerando-se que a base teórica, política e ideológica do Projeto Ético Político do Serviço Social tem como centralidade o marxismo, quais as possibilidades postas à/ao assistente social escolar para se posicionar frente aos processos de constituição de si do sujeito escolar juvenil, centrados numa estética da existência que foge à normalização das condutas prescritas pela instituição escolar?

Para buscar possibilidades de respostas a tal questão, tomamos como inspiração teórica o pensamento do filósofo Michel Foucault, de modo mais específico a noção de estética da existência, o que nos leva a implicarmo-nos com outras noções que se acoplam a essa, tais como: discurso, prática, cuidado de si, governamentalidade e constituição do sujeito. Como base empírica para desenvolver as nossas reflexões, apoiamo-nos no exame de dois documentos elaborados pelo Conselho Federal de Serviço Social - CFESS, que se complementam ao tomarem como propósito a análise da trajetória do Serviço Social no Brasil e as proposições acerca do trabalho do assistente social escolar.

O primeiro documento é o artigo intitulado "A inserção do Serviço Social na Política de Educação na perspectiva do Conjunto CFESS/CRESS: elementos históricos e desafios para a categoria profissional", publicado na Revista SER Social (2012), e o segundo documento, intitulado "Subsídios para a Atuação de 
Assistentes Sociais na Política de Educação", publicado pelo CFESS (2012), é uma brochura produzida pelo Grupo de Trabalho Nacional Serviço Social na Educação. O primeiro documento é importante no contexto de elaboração deste estudo porque assinala o percurso histórico do Serviço Social no Brasil e os desafios do presente enfrentados pelo/a assistente social no âmbito da escola; o segundo nos é importante por apresentar a concepção de educação que deve nortear o trabalho do/a assistente social na escola e descreve as competências e atribuições desse/a profissional no âmbito da educação, bem como as dimensões, as particularidades e as estratégias firmadas pela categoria para a inserção, atuação e consolidação do exercício profissional do/a assistente social no campo educacional, de acordo com o projeto ético-político e profissional do/a assistente social.

Em relação à estética da existência estudantil, podemos pensar sobre a escola a partir da demarcação de três períodos históricos: 1ำ - de 1549 a 1930; ํㅜ de 1930 a 1990; e 3ำ - de 1990 aos dias atuais. É nos dois últimos períodos que localizamos a ação do/a assistente social no campo educacional, e em cada período, as suas práticas são orientadas por matrizes de pensamento diferenciadas. No caso escolar, é no $3^{\circ}$ período que se situam possibilidades de o estudante, na escola, desenvolver práticas de constituição de si a partir de uma ética de si. Do mesmo modo, é neste período que o/a assistente social poderá lidar com estudantes de modo a favorecer vivências orientadas na perspectiva da estética da existência.

\section{DAS POSSIBILIDADES DA ESTÉTICA DA EXISTÊNCIA NA ESCOLA}

A escola brasileira, de 1549 até a década de 1930 assumiu uma perspectiva elitista, racista e patriarcal, haja vista destinar-se apenas às crianças e jovens do sexo masculino, brancos e de condições econômicas favorecidas. Neste sentido, em uma sociedade cuja economia se assentava na agricultura, as relações de poder, de governo e de mando espraiadas por todo o tecido social estavam centradas de modo efetivamente vertical nas mãos de sujeitos do sexo masculino e a cultura se organizava a partir de postulados religiosos orientados pela Igreja Católica. A escola e os seus sujeitos, isto é, gestores, professores e alunos seguiam e exerciam fortemente a moral prescrita pela igreja, pela família e pelo Estado e suas agências. Neste caso, salvo algumas exceções, alvos de punição exemplar, as possibilidades de subversão dos sujeitos estudantis à moral instituída eram remotas. 
A proclamação da República, em 1889, a incipiente urbanização e industrialização no começo dos anos 1900, as reformas da educação na década de 1920, a Revolução de 30 e a emergência dos ideais dos Pioneiros da Educação Nova e o seu Manifesto de 1932 vão produzindo pequenas alterações sociais, econômicas e políticas que vão ensejar o início de feições modernas à escola brasileira, forjando nesta novas configurações importantes, a exemplo da busca pela sua laicização, estatização e abertura à parte da classe trabalhadora e às pessoas de sexo feminino - a emergência da escola pública, estatal, laica e de coeducação para todos - como apregoada pelo ideário liberal escolanovista (GHIRALDELLI JUNIOR, 2006).

Com os processos de transformação e expansão vivenciadas pela escola brasileira a partir dos anos 1930, pautadas na escolarização para a formação da mão de obra destinada à indústria e ao comércio e das demandas suscitadas pelo processo de urbanização, por um lado, e por outro para a formação superior, a escola brasileira, de feição moderna, se constitui com todo o aparato e "tecnologias do poder disciplinar", materializando a perspectiva do "vigiar e punir" (FOUCAULT, 1987). Neste sentido, arregimenta um corpo de profissionais formados em tal perspectiva, tais como os professores, pedagogos, em suas diversas funções, tais como o/a diretor/a de escolas, o supervisor escolar voltado ao trabalho dos professores e o orientador educacional destinado à supervisão e ao aconselhamento dos estudantes, o assistente social e o psicólogo. Assim, além dos professores, a escola disporá de profissionais qualificados para o trabalho de gestão dos processos pedagógicos disciplinares, fazendo cumprir-se a moral estabelecida e engendrando a formação de sujeitos assujeitados.

Todavia, nos anos de 1960 parte dos jovens estudantes secundaristas e universitários implicados no movimento estudantil produziram problematizações e movimentos de contestação à moral social e política estabelecida, criando possibilidades de emergência de estética da existência na constituição de si ao elaborar críticas à moral vigente. É possível entendermos tais críticas na perspectiva assinalada por Foucault (1990, p. 5), que define a crítica como a prática da "arte da inservidão voluntária e da indocilidade refletida", mas esse movimento construído pelos estudantes, num panorama sociopolítico nacional envolvendo outros sujeitos, se defrontou com dois obstáculos. 
O primeiro foi o atrelamento das entidades estudantis a partidos políticos, a exemplo do Partido Comunista do Brasil, que operava com uma moralidade préestabelecida e um sistema rígido de disciplinaridades que buscava assegurar tal moralidade. Do mesmo modo, havia os estudantes que militavam no movimento estudantil e que estavam vinculados às pastorais estudantis da Igreja Católica, instituição essa que também rege a vida dos seus fiéis por meio de uma moralidade determinada e dogmática materializada em um sistema rígido de disciplina.

O segundo foi a Ditadura Militar, instituída com o golpe de 1964, que a partir do Ato Institucional n. 5, em 1968, cassou a liberdade de organização e manifestação política de civis, desmantelou as entidades estudantis, produziu reformas no sistema de ensino nos diversos graus de forma autoritária, perseguiu os estudantes com violenta repressão física e moral, impondo exílios e cometendo assassinatos de estudantes que se colocaram contrários ao regime antidemocrático.

Assim, ao fim da ditadura militar, em 1985, e em meio às transformações sociais, econômicas, políticas e culturais ocorridas a partir da década de 1990, os efeitos da revolução tecnológica e as crises que aí tomam monta nas diversas instituições sociais, apontando à escola crise de demandas já configuradas e crise de sentido para o processo educativo (TEDESCO, 1998), os jovens vão assumindo posição de sujeitos de direitos e de criatividade.

Neste contexto de transformações sociais e de crises, os jovens estudantes vivenciam possibilidades de construção de processos de constituição de si, haja vista que, conforme assinala Peralva (2007, p. 25): "Enquanto o adulto vive ainda sob o impacto de um modelo de sociedade que se decompõe, o jovem já vive em um mundo radicalmente novo, cujas categorias de inteligibilidade ele ajuda a construir". Assim, as novas configurações sociais, políticas, culturais e educacionais colocam as condições de possibilidade para os sujeitos escolares, a exemplo dos/as estudantes e dos/as assistentes sociais, pensarem, problematizarem e constituírem as suas atuações no âmbito da escola e da vida estudantil.

\section{SERVIÇO SOCIAL E EDUCAÇÃO}

No Brasil, na década de 1930, se desenvolvem as condições objetivas para a instauração de um programa de redimensionamento do Estado, cuja função é a de promover a reprodução ideológica e material da classe trabalhadora através da 
articulação de um conjunto de políticas sociais que amenizassem as tensões provocadas pela ordem burguesa. Surgia então as condições para a criação de um espaço sócio ocupacional para as/os profissionais do Serviço Social e sua inserção na divisão social e técnica do trabalho, o que requisitou deste/a profissional um determinado perfil capaz de objetivar as demandas em soluções imediatas e concretas, ou paliativas, de acordo com a situação que lhe chegasse.

No perfil do/a profissional, para ser bem-sucedido/a deveria ser bemeducado/a, ter a capacidade de adentrar às intimidades dos clientes, ter uma aparência despojada e simples, com seriedade e a ternura que fazem dele/a "o profissional da ajuda", do aconselhamento, da indulgência. Assim, a constituição de uma determinada imagem social para os/as assistentes sociais, consequentemente, para a profissão, está intimamente relacionada ao projeto de sociedade burguês, o qual the assegura um determinado espaço na divisão sócio técnica do trabalho, vinculado às particularidades da trajetória social e histórica brasileira, marcada por traços de décadas de subalternização e dependência estrangeira. Essa vinculação atravessa a gênese da profissão e se expressa nas determinadas formas de agir e de pensar dos/as agentes profissionais e na conformação à determinada imagem social para a profissão.

Mas a partir de meados da década de 1960 se observa no Serviço Social brasileiro um processo progressivo de amadurecimento e construção de uma direção social para a profissão, demarcado pela crítica e recusa do conservadorismo na profissão. Este é um momento de transição em que a realidade objetiva sinalizava a necessidade de mudanças no arcabouço teórico metodológico da profissão e que o histórico conservadorismo pode ser contestado diante das exigências políticas e sociais impostas pela ruptura com a ordem ditatorial. A renovação iniciada a partir dos anos pode ser dividida em três momentos distintos: no primeiro momento foi a da Renovação Conservadora, compreendido entre os anos 1960 e 1970; o segundo momento denominado de Reconceituação do Serviço Social, que vai da década de 1970 a 1980 e o terceiro, já no final de década de 1980 , chamado de Reaproximação da profissão com o marxismo.

Na transição dos anos 1970 para os anos 1980, o Serviço Social é marcado pelo momento reconhecidamente importante em sua trajetória histórica: a crítica ao conservadorismo profissional (Movimentos de Reconceituação), já em discussão na América Latina desde a segunda metade dos anos 1960. Contudo, na passagem 
dos anos 1970 para os anos 1980 no Brasil, essa discussão é posta em foco privilegiado, na medida em que coincidiu com a crise da Ditadura brasileira, exercida desde abril de 1964, e provocou a categoria profissional dos/as assistentes sociais a repensar e discutir a orientação dada à sua prática profissional, face às demandas criadas e instauradas no período ditatorial cujos prejuízos de ordem social e política marcam a conjuntura brasileira.

Desta forma tem início a construção de um novo projeto profissional cuja característica principal é a vinculação orgânica às demandas e interesses da classe trabalhadora. Este origina-se a partir de dois processos: um ligado a própria profissão e resultado do acúmulo teórico e político advindo da interlocução de segmentos minoritários, à época, chamado de "Movimento de Reconceituação", e outro ligado à conjuntura de transição democrática no Brasil nos anos 1980, cujo desfecho principal foi a promulgação da Constituição Federal em 1988.

Esse projeto vai requisitar uma ação profissional cuja necessidade é a de construir uma nova proposta de atuação tendo em vista as demandas e os interesses da classe trabalhadora, assumindo como fundamento um posicionamento laico. No entanto, o fato desta autoimagem visível no projeto profissional que atualmente norteia a profissão, se apresentar hegemonicamente entre suas entidades, não significa que tenha eliminado os traços da imagem socialmente consolidada. Há uma tensão entre os traços tradicionais, que conformaram historicamente a imagem da profissão desde sua emergência na divisão social e técnica do trabalho, e outros novos, emergentes do salto qualitativo experimentado pelo Serviço Social nas últimas décadas, os quais convivem dialeticamente. Esta tensão, marcada por continuidades e rupturas, atravessa a imagem da profissão, configurando-a enquanto uma totalidade constituída dialeticamente por dupla face: a imagem social e a autoimagem profissional, diversos lados da mesma unidade: a imagem da profissão (ORTIZ, 2010).

Isso posto, ao pensarmos sobre a trajetória do serviço Social na educação constatamos que este não é um espaço sócio ocupacional recente, mas um espaço significativo de atuação profissional. Todavia, apesar desta longa trajetória, as produções teóricas na área e a inserção profissional não tem alcançado grande visibilidade e se manifestam de forma pulverizada, o que dificulta um debate de maior fôlego na categoria e a conformação de uma identidade e reconhecimento social da profissão na área (CFESS/CRESS, 2011). 
No Brasil, a inserção do Serviço Social no campo da educação é demarcada desde a sua gênese, na década de 1930, como demanda do Estado, semelhante às demais áreas de atuação na época. A primeira relação entre a educação e o Serviço Social estabeleceu-se pela via da educação para o trabalho, enquanto maneira de direcionar as "classes menos favorecidas da sorte" para uma ocupação, momento do Estado populista, em que se manifestou a ênfase no desenvolvimento de condições econômicas, políticas e sociais, destinadas à industrialização do país com configuração posta pelo padrão capitalista.

O Serviço Social era a ponte de ligação entre a família e a escola, desempenhando uma função integradora, tomando a educação para o trabalho como condição de adaptação social sob a ideologia do messianismo da educação para a transformação da sociedade, ideologia que naquele momento empolgava o mundo. Conforme Pinheiro (1985, p. 45):

A influência escolar auxiliada pelo Serviço Social penetra na família e a mobiliza para servir a criança com orientação mais própria. Toda essa atividade incide também sobre a organização e orientação das atividades escolares. Todos os recursos ao seu alcance são mobilizados em auxílio das famílias e dos alunos de maneira a poderem as classes menos favorecidas usufruir de mais vantagens da escola; o que diminui os desajustamentos [...].

Neste caso, o/a profissional era requisitado/a a intervir em situações escolares consideradas desvio, defeito ou anormalidades sociais, e dessa maneira, a atuação do Serviço Social baseava-se na mediação de conflitos de caráter individual e familiar, bem como na prevenção e na cura de desajustamentos por parte da família ou do/a estudante.

$\mathrm{Na}$ primeira década da ditadura militar, a educação era entendida e amplamente difundida como instrumento eficaz e capaz de realizar a passagem do subdesenvolvimento para o desenvolvimento. Assim, passou a ser consagrada mundialmente com esta função e utilizada pelos protagonistas do governo e dos setores sociais, onde a prática do Serviço Social se relacionava diretamente com a educação para o trabalho sobre vários aspectos, mas principalmente como forma de incentivo e motivação das populações à aceitação e integração ao novo padrão capitalista que estava se consolidando no país.

A ênfase dada à profissão de Serviço Social durante o período ditatorial se alicerçava na prática promocional desenvolvida pelos/as profissionais que se 
encaixava perfeitamente nos objetivos governamentais, nos quais a educação para o trabalho estava presente. Desta maneira, configurou-se o quadro que efetivamente associou o Serviço Social à educação.

Com o processo de amadurecimento da profissão, vários episódios marcaram a evolução do debate do Serviço Social educacional, como o III CBAS (Congresso Brasileiro de Assistentes Sociais), que ficou conhecido como o Congresso da Virada, em 1979, onde abordou o tema "Serviço Social e Política Social" com ênfase nas políticas de Educação, Assistência Social, Habitação, Menor, Previdência Social, Saúde e Trabalho. Outro episódio foi o V CBAS, em 1985, sobretudo porque registra o avanço no interior da categoria no que se refere as questões levantadas sobre a prática profissional desenvolvida na educação. E posteriormente, "[...] a partir da década de 1990, em consonância com o amadurecimento do Projeto Ético Político profissional, visualiza-se no Brasil um considerável aumento do profissional em Serviço Social na área de educação" (CFESS/CRESS, 2011, p.5).

Esse projeto profissional vem a afirmar a defesa dos direitos humanos e a recusa do preconceito e arbítrio, contemplando o pluralismo; posiciona-se a favor da equidade e da justiça social; da ampliação e consolidação da cidadania, visando garantir os direitos civis, políticos e sociais da classe trabalhadora, enquanto socialização da participação política e da riqueza produzida socialmente. Assim, nos últimos anos a profissão vem modificando substancialmente seus rumos éticospolíticos e atualmente a categoria expressa o compromisso com a construção de uma nova ordem societária com a democracia e a garantia de direitos universais, acompanhando as transformações na sociedade brasileira, afastando-se de uma concepção de ajustamento e seguindo um posicionamento político e ideológico.

Neste sentido, a preocupação da categoria com as questões que afetam a educação é consequência da maturidade teórico-metodológica e ético-política conquistada nas últimas décadas, uma vez que os espaços que compõem o campo sócio ocupacional da educação são tensionados por contradições e interesses em disputa, lutas de classes e correlações de força. Almeida (2005, p.10) assevera que a luta pela educação se constitui numa das expressões da questão social, pois "a política educacional pode ser concebida também como expressão da própria questão social na medida em que representa o resultado das lutas sociais travadas pelo reconhecimento da educação pública como direito social". 
Compreender a questão social a partir de sua gênese remete ao conflito entre capital e trabalho e aos avanços e retrocessos das políticas sociais resultantes dos conflitos entre os segmentos sociais. Desta forma, a educação como política social se configura como uma das respostas de Estado às demandas que emergem como expressão das desigualdades na sociedade capitalista. E a ampliação das refrações da questão social se manifestam também no cotidiano da escola: "a educação organizada sob a forma de política social se constitui em uma das práticas sociais mais amplamente disseminadas de internalização dos valores hegemônicos na sociedade capitalista" (CFESS/CRESS, 2011, p. 12).

Neste caso, o/a assistente social deverá debruçar-se sobre a realidade das instituições no campo da educação como totalidade, destacando suas contradições, tendo clareza de que ela é constituída por mediações, processos e estruturas inseridas na realidade social e que necessitam ser analisadas.

Essa análise só poderá ser efetivada se o/a assistente social tiver claro qual o significado da educação pública e da escola no âmbito da cultura, o que no entender de Gramsci (1975), não significa simplesmente aquisição de conhecimentos, mas um posicionamento crítico diante da história buscando conquistar a liberdade, porque vislumbra possibilidades de circulação de contra ideologias. Assim, a contribuição do Serviço Social, segundo Martins (2007), poderá ser uma alternativa construtiva, visando unir esforços com os educadores e usuários da escola pública para lutar por reformas significativas na rota histórica de transformação da escola, para se efetivar uma educação mais democrática, unitária, como tem sido divulgado pelos movimentos e organizações de educadores, bem como de estudantes.

\section{ESTUDANTES, ASSISTENTE SOCIAL E ESTÉTICA DA EXISTÊNCIA NA ESCOLA}

Devido às transformações societárias, principalmente a partir do século $X X$, as instituições ligadas à educação precisam de aporte profissional e social para desempenhar as suas funções educativas, pois essas instituições, privadas e públicas, que pertençam à rede de proteção social para o atendimento à criança, ao adolescente e às famílias necessitam da escola para efetivar as ações sócio educativas. Isto porque a escola é um espaço adequado para o desenvolvimento de ações educativas e preventivas ligadas a várias situações sociais e culturais que 
afetam o cotidiano da população pobre que, na maioria das vezes, possui apenas a escola como equipamento social.

A contribuição do/a Assistente Social nos espaços ocupacionais da educação para a efetivação da democratização da educação é o da luta pela ampliação do acesso da população à escola pública, e/ou de promover a participação de todo o corpo escolar nas instâncias decisórias existente na escola, na relação entre a família com a escola e entre a comunidade e a sociedade. Neste sentido, as principais demandas que necessitam de intervenção do Serviço Social na área de educação são: "baixo rendimento escolar; evasão escolar; desinteresse pelo aprendizado; problemas com indisciplina; insubordinação a limites ou regras da escola; vulnerabilidade às drogas; comportamentos agressivos ou violentos" (CFESS, 2011, p. 23).

Destarte, acredita-se que o aluno enquanto sujeito individual não tem grande participação na transformação dessa realidade, ao passo que coletivamente pode fazer a diferença, pois enquanto sujeito histórico pode influenciar na diminuição das desigualdades e na luta por equidade. Bem como a escola, por si só, não irá transformar a sociedade, até porque ainda não conseguiu se transformar enquanto instituição, apesar dos avanços alcançados. Contudo, ela também é um espaço para a realização da tarefa de construção de uma sociedade onde os indivíduos, coletivamente, possam participar ativamente do processo social, político, cultural e econômico.

Diante de tais afirmações, corroboramos a ideia de que a educação não pode consistir meramente em informações ou instruções e processos que possibilitem aos indivíduos ter apenas conhecimento de seus direitos e deveres para conformaremse. Ao contrário, acreditamos que uma educação que prepare para a democracia deva preparar o aluno para assumir a sua posição de governante, no sentido de ser aquele que se envolve com a ação política local e social, que age ativamente do exercício dos direitos sociais e humanos e que busca governar as próprias ações.

Sendo assim, embora a atuação do Serviço Social na educação ainda envolva ações relacionadas a diagnóstico de problemas sociais que pudessem interferir no desempenho escolar dos alunos, sua contribuição nos dias atuais na eliminação ou atenuação desses problemas deve se direcionar sempre na perspectiva de efetivação do direito à educação, visando à formação para o exercício consciente da cidadania, conforme o Projeto Ético Político da Profissão do 
assistente social. A partir deste Projeto, o abandono da perspectiva do assistencialismo e o implemento de perspectiva crítica e reflexiva, visando uma atuação em prol da democracia escolar, centrada na luta pelo direito à educação e no exercício da cidadania dos sujeitos estudantes demarcam as condições de possibilidade de o assistente social contemplar no seu trabalho a estética da existência. Todavia temos aí algumas implicações importantes a considerar.

O Projeto Ético Político do/a assistente social que deve nortear a atuação deste/a profissional se assenta no referencial marxista e toma como paradigma a centralidade da luta de classes. Porém, essa atuação precisa estar em consonância com as questões que interferem ou podem interferir nos objetivos de trabalho do/a assistente social, e entre essas questões podemos assinalar a presença de diferentes subjetividades que informam a estética da existência de sujeitos estudantes que não desfrutam de aceitação moral por parte da escola. De acordo com Souza (2008, p. 201):

Diferentes fenômenos, subjetividades e objetividades inserem-se no âmbito escolar, reestruturando 0 seu processo educativo $e$ condicionando a comunidade escolar em suas escolhas, atitudes e necessidades. Conhecer e interpretar esses fenômenos é uma atitude profissional indispensável para qualificar a intervenção do Assistente social nas demandas concretas surgidas no âmbito de atuação, da problemática surgida na escola.

A atuação orientada por um paradigma cuja centralidade seja a luta de classes teria condições de atender demandas escolares calcadas nas questões da subjetividade e da ética de si? Em princípio, embora concordemos com Valeirão (2017, p. 20) quando afirma que "Colocar Marx e Foucault em polos antagônicos parece-nos, no mínimo, um devaneio falacioso! ", é necessário pontuar as diferenças de matriz do pensamento de Marx e de Foucault, pois enquanto para o primeiro o devir humano seria a revolução socialista, para o segundo, o devir não tem destino pré-determinado. Entretanto, é preciso atentar também que para Foucault não há a negação da luta de classes, e sim, uma extrapolação ou não centralidade desta, haja vista que há outras lutas que se afiguram tão importantes quanto a luta de classes, tais como as relações saber-poder, as questões relacionadas às sexualidades, ao governo de si e dos outros, aos processos de subjetivação, entre outras, nas quais são consubstanciadas questões como a geracional, de gênero, 
étnico-raciais, orientação sexual que implicam na constituição e governamentalidade dos sujeitos etc.

Assim, sem desconsiderar a perspectiva da luta de classes, o que seria impossível no nosso contexto social, político e econômico, nos perguntamos se o paradigma apontado seria suficiente para dar conta da complexidade de todas as questões que consubstanciam o cotidiano escolar e as políticas de educação e demandam a intervenção do/a assistente social. Ou, colocando a pergunta de outro modo, seria a orientação ético-política centralizada na luta de classes uma impossibilidade para o/a assistente social atuar em acordo com a noção de estética da existência na relação com os estudantes? Parece-nos que não! Neste sentido, Brasil (2001, p.168) faz as seguintes afirmações:

[...] o assistente social poderá assumir uma relação crítica nas relações de poder-saber e, portanto, uma atitude ético-política ante os problemas de governo, contrapondo-se à sujeição e à dominação. E se o fizer como sujeito portador de uma ética de governo de si e dos outros, assume uma postura interventiva que se caracteriza pela luta contra o estado de dominação e a domesticação do homem que nega sua condição de sujeito criador e inventor de si. É o que Foucault chama de uma produção estética da existência.

Para esta autora, a estética da existência não apenas pode ser uma noção a orientar o trabalho do assistente social, mas também pode aferir sustentação à própria constituição do assistente social enquanto categoria profissional, ao asseverar que:

Sem medo de sermos reducionistas, podemos dizer, com algumas
reservas, que em três momentos históricos, os assistentes sociais
como sujeitos individuais e coletivos se colocaram à ética o problema
da organização da existência: quando fizeram o Movimento de
Reconceituação, quando construíram a Associação Nacional dos
Assistentes Sociais - ANAS, e até mesmo quando elaboraram um
novo Código de Ética para a profissão, e, principalmente quando
perguntaram "Quem somos?". Sujeitos sujeitados! Sujeitos criativos!
Sujeitos rebelados! Sujeitos amordaçados! Sujeitos revolucionários!
Sujeitos moderados! Mas acima de tudo, sujeitos governados e
governantes. E continuam a fazê-lo no enfrentamento das múltiplas
lutas do cotidiano institucional e social. (BRASIL, 2001, p. 170).

Sobre as possibilidades de atuação do/a assistente social na escola contemplando-se a estética da existência dos estudantes, nossas análises sobre os dois documentos que constituem a base empírica deste artigo indicam diversos 
apontamentos que respaldam tal atuação profissional. Neste caso, o primeiro apontamento a ser elencado se refere à concepção de educação e aos objetivos que devem orientar a atuação do/a assistente social na escola, tendo por pressuposto a noção de educação emancipatória e a explicitação da concepção de emancipação. Assim, se lê no "Subsídios para a Atuação de Assistentes Sociais na Política Educacional" (CFESS, 2012, p. 22), o seguinte:

A concepção de emancipação que fundamenta esta concepção de educação para ser realizada depende também da garantia do respeito à diversidade humana, da afirmação incondicional dos direitos humanos, considerando a livre orientação e expressão sexual, livre identidade de gênero, sem as quais não se viabiliza uma educação não sexista, não racista, não homofóbica/lesbofóbica/ transfóbica.

Neste caso, a garantia ao respeito à diversidade humana e à incondicionalidade dos direitos humanos apontam para as diversas estéticas da existência que se fazem presentes na escola, sejam essas sexuais, artísticas, de gênero, étnicas e políticas. Também, em relação às atribuições e competências de assistentes sociais, os documentos, ao indicarem modos do fazer profissional, assinalam o trato respeitoso e a abordagem desprovida de preconceitos linguísticos, teóricos e o acolhimento de sujeitos, indivíduos ou grupos, que produzem estilos de vida não convencionados na esfera escolar, e que se constituem na diferença.

Assim, nas orientações aos/as assistentes sociais (CEFSS, 2012), constam que esses/as devem: "Orientar indivíduos e grupos de diferentes segmentos sociais no sentido de identificar recursos e de fazer uso dos mesmos no atendimento e na defesa de seus direitos" (p. 28); desenvolver "Empenho na eliminação de todas as formas de preconceito, incentivando o respeito à diversidade, à participação de grupos socialmente discriminados e à discussão das diferenças” (p. 32).

Outro ponto que se refere às possibilidades do trato com a estética da existência diz respeito às condições para os/as profissionais do serviço social desenvolverem o seu trabalho e que correspondem ao cuidado de si e ao governo de si e dos outros. Neste sentido, o documento do CFESS (2012), afirma que esses/essas profissionais devem exercer o serviço social "sem ser discriminado/a, nem discriminar, por questões de inserção de classe social, gênero, etnia, religião, 
nacionalidade, orientação sexual, identidade de gênero, idade e condição física" ( $p$. 33), e "abster-se, no exercício da Profissão, de práticas que caracterizem a censura, o cerceamento da liberdade, o policiamento dos comportamentos, denunciando sua ocorrência aos órgãos competentes" (p. 35). Neste caso, se faz importante destacar que a preocupação com o governo do outro, em favor da sua governamentalidade, também requer práticas de liberdade, ou seja, a ética de si do sujeito que governa para que os sujeitos em questão, a exemplo do/a assistente social e do/a estudante, possam produzir as suas vidas implicando-as como exercício das artes da existência.

Todavia, vale lembrar que a produção de estéticas da existência, principalmente no caso dos jovens, pode ser manifesta no campo do sujeito individuo ou do sujeito coletivo, pois é comum entre os jovens a afirmação de si junto a um grupo de pertença, no caso, as galeras, as tribos, as turmas etc. Nesta perspectiva, ainda que o CEFSS coloque em questão a pertinência e a abrangência do trabalho do/a assistente social direcionada ao indivíduo, haja vista a centralidade no coletivo por conta do seu aporte teórico político centrado na luta de classes sociais, este abre espaço e possibilidade de atuação junto ao indivíduo. De acordo com o documento produzido por esse Conselho (CFESS, Ibid, p. 51):

As abordagens individuais e a atuação junto às famílias são bastante necessárias e estratégicas ao trabalho profissional, visto que delas dependem muito a capacidade de enfrentamento das situações de ameaça, violação e não acesso aos direitos sociais, humanos e à própria educação, como também de sua maior visibilidade no âmbito da política educacional, mas não devem constituir na única modalidade de intervenção profissional.

Como nos foi possível vislumbrar a partir do exame aos dois documentos referidos, são muitas as possibilidades de atuação do/a assistente social junto a jovens estudante no âmbito da escola, tendo em vista a produção de estéticas da existência desses sujeitos, ou seja, estilos de vida centrados numa ética de si, calcada na diferença em relação à moral remetida à escola e à moral escolar. São estilos de vida cuja estética se assentam em performances derivadas das suas condições físicas, sociais, políticas, da sua sexualidade, do seu gênero, da sua etnia a partir das quais esses sujeitos, na condição de jovens estudantes elaboram como modos de se colocarem e se afirmarem do mundo, seja como pessoas ou como agrupamentos que engendram singularidades. Aliás, essas possibilidades éticas e 
estéticas de existência colocam-se mesmo para o sujeito assistente social enquanto se constitui a si mesmos como indivíduo e como categoria profissional.

\section{CONCLUSÃO}

Neste artigo, tratamos das possibilidades do sujeito estudante, no âmbito da escola, se produzirem como sujeitos não assujeitados à moral estabelecida, constituindo a si mesmo por meios de processos exercidos a partir de uma ética de si, e como a atuação do/a assistente social escolar pode se colocar a serviço dos jovens estudantes em seus processos de produção de estéticas da existência por si produzidas, e fortalecer as lutas dos jovens estudantes em função da conquista da sua condição de sujeito de direitos, de autonomia política e estética nos processos de constituição de si.

Trabalhamos com a hipótese de que devido o histórico do Serviço Social ter se vinculado, por muito tempo, à perspectiva assistencialista e disciplinar, e o direcionamento teórico, ético e político-ideológico assumido nos documentos que instituem o projeto de formação e de atuação do profissional do assistente social, por ser elaborado sobre matriz marxista, cuja centralidade é a luta de classes, seria empecilho para que este/a profissional atuasse em função dos processos de constituição de si, da ética de si que ensejam estéticas da existência dos estudantes. Esta hipótese não foi confirmada.

As análises sobre a base empírica do estudo nos mostraram que os/as assistentes sociais, amparados pelo Código de Ética Profissional da categoria e pelo Projeto ético-político da profissão, gozam de possibilidades efetivas de trabalharem junto aos jovens estudantes assumindo a perspectiva da estética da existência. $O$ sentido de emancipação humana como base de sustentação da concepção de educação, e as lutas em prol do respeito à diversidade humana e do asseguramento dos direitos humanos como objetivos postos à prática do trabalho do/a assistente social dão-lhe condição de possibilidade para atuarem na perspectiva da estética da existência.

Desse modo, concluímos o artigo assinalando a pertinência da atuação dos/as assistentes sociais na perspectiva da estética da existência no âmbito da educação, e de modo mais específico, na esfera da escola pública, para contemplar as problemáticas contemporâneas referentes às questões de gênero, étnico-raciais 
e diversidade sexual que tem trazido significativo prejuízo à escolarização de mulheres, de pessoas negras e pardas, homossexuais, lésbicas, travestis, transexuais e transgênero, vítimas de machismo, racismo, LGBTTfobia que muitas vezes se evadem da escola devido ao bullying ou à violência física.

\section{REFERÊNCIAS}

ALMEIDA, Ney Luiz Teixeira. Parecer sobre projetos de lei que dispõem sobre a inserção do Serviço Social na educação. Caderno Especial, n.26, 2005. Disponível em: http://www.assistentesocial.com.br/novosite/cadernos/cadespecial26.pdf Acesso em: junho/2018.

BRASIL, Glaucíria Mota. A Ética na profissão como estética da existência. Serviço Social \& Sociedade, São Paulo, v. 1, n.65, p. 166-171, 2001.

CONSELHO FEDERAL DE SERVIÇO SOCIAL - CFESS. Subsídios para o debate sobre o Serviço Social na educação. Brasília: DF, 2011.

\section{Educação. Brasília, DF, 2012}

\section{Subsídios para a Atuação de Assistentes Sociais na Política de}

. A inserção do Serviço Social na Política de Educação na perspectiva do Conjunto CFESS/CRESS: elementos históricos e desafios para a categoria profissional. SER Social, Brasília, v. 14, n. 30, jan./jun. 2012, p. 244-258.

FOUCAULT, Michel. Vigiar e Punir: Nascimento da prisão. Tradução de Raquel Ramalhete. Petrópolis: Vozes, 1987.

. O que é a crítica? Tradução de Gabriela L. Borges. In: Espaço Michel Foucault. 1990. Disponível em: http://michelfoucault.weebly.com/uploads/1/3/2/1/13213792/critica.pdf. Acesso em: 23 de novembro de 2014.

. Ditos e escritos. Ética, sexualidade, política. MOTTA, Manoel Barros da (Org.). Tradução de Elisa Monteiro e Inês Autran Dourado Barbosa. Rio de Janeiro: Forense Universitária, 2004. v. 5.

Sobre a genealogia da ética. Uma revisão do trabalho. In: RABINOW, Paul; DREYFUS, Hubert. Michel Foucault. Uma trajetória filosófica. Para além do estruturalismo e da hermenêutica. Rio de Janeiro: Forense Universitária, 2013.

GHIRALDELLI JUNIOR, Paulo. História da Educação Brasileira. São Paulo: Cortez, 2006.

GRAMSCI, Antônio. Cadernos do Cárcere. Tradução Carlos Nelson Coutinho. Rio de Janeiro: Civilização Brasileira, 1975. 
MARTINS, Eliana Bolorino Canteiro. Educação e Serviço Social: elo para a construção da cidadania. 2007. Tese (Doutorado em Serviço Social). Faculdade de Serviço Social, Pontifícia Universidade Católica de São Paulo, São Paulo.

ORTIZ, Fátima Grave. O Serviço Social no Brasil: os fundamentos de sua imagem social e da autoimagem de seus agentes. Rio de Janeiro: E-papers, 2010.

PERALVA, Angelina T. O jovem como modelo cultural. In: FÁVERO, Osmar et al (Orgs.) Juventude e contemporaneidade. Brasília: UNESCO, MEC, ANPED, 2007, p. 13-27.

PIGANATELLI, Frank. Que Posso Fazer? Foucault e a Questão da Liberdade e da Agência Docente. In: SILVA, Tomaz T. da $\left(\mathrm{Org}^{\circ}\right)$. 0 sujeito da educação: Estudos Foucaultianos. Petrópolis: Vozes, 1994.

PINHEIRO, Maria Esolina. Serviço Social, infância e juventude desvalidas. São Paulo: Cortez; Rio de Janeiro: Centro de Produção da UERJ, 1985.

SOUZA, Iris de Lima. SERVIÇO SOCIAL NA EDUCAÇÃO: saberes e competências necessários no fazer profissional. 2008. Tese (Doutorado em Educação). Centro de Ciências Sociais Aplicadas, Universidade Federal do Rio Grande do Norte, Natal.

TEDESCO, Juan C. O Novo Pacto Educativo: educação, competitividade e cidadania na sociedade moderna. Tradução de Otacílio Nunes. São Paulo: Ática, 1998.

VALEIRÃO. Kelin. Foucault y el maxismo. Cuestiones de filosofia. V. 3, n. 20, enero/junio, 2017. 